\title{
Editorial: Animal Mass Mortalities in Aquatic Ecosystems: How Common and Influential?
}

\author{
Gary A. Lamberti ${ }^{1 *}$, Natalie M. Levesque ${ }^{1}$, Michael A. Brueseke ${ }^{1}$, Dominic T. Chaloner ${ }^{1}$ \\ and M. Eric Benbow ${ }^{2,3}$ \\ ${ }^{1}$ Department of Biological Sciences, University of Notre Dame, Notre Dame, IN, United States, ${ }^{2}$ Department of Entomology, \\ Michigan State University, East Lansing, MI, United States, ${ }^{3}$ Department of Osteopathic Medical Specialties, Michigan State \\ University, East Lansing, MI, United States
}

Keywords: mass mortality, resource subsidy, animal migrations, insect emergence, ecosystem function, programmed death

Editorial on the Research Topic

Death and Decomposition in Aquatic Ecosystems

\section{INTRODUCTION}

The prototypical animal mass mortality in aquatic ecosystems is the annual spawning migration of Pacific salmon (Oncorhynchus spp.) that can transport thousands of kilograms of labile organic resources to rivers and lakes. However, many other mass die-offs of vertebrates and invertebrates can strongly influence the structure and function of aquatic ecosystems. Here we discuss the spatial and temporal occurrence of mass mortality events in aquatic and riparian systems, as informed by

OPEN ACCESS

Edited and reviewed by: Dennis Murray,

Trent University, Canada

*Correspondence: Gary A. Lamberti glambert@nd.edu

Specialty section: This article was submitted to Population and Evolutionary Dynamics,

a section of the journal Frontiers in Ecology and Evolution

Received: 02 September 2020 Accepted: 18 September 2020 Published: 12 November 2020

Citation:

Lamberti GA, Levesque NM

Brueseke MA, Chaloner DT and Benbow ME (2020) Editorial: Animal

Mass Mortalities in Aquatic

Ecosystems: How Common and Influential?

Front. Ecol. Evol. 8:602225 doi: 10.3389/fevo.2020.602225 the preceding series of papers in this special issue, and their influence on ecological processes. Fish in the families Salmonidae and Clupeidae undertake annual mass migrations that often result in their death in the ecosystem where they spawn, and therefore their macronutrients $(C, N, P)$ and even micronutrients subsidize recipient ecosystems. In contrast, stressful conditions such as oxygen depletion or toxic algal blooms can result in unpredictable fish and mussel die-offs. Terrestrial animals ranging from insects to wildebeest also subsidize aquatic and riparian ecosystems during mass mortality episodes associated with migrations or adult emergence from or near water bodies. We propose a paradigm of "programmed vs. catastrophic" death whereby recipient ecosystems vary along a gradient in their history and capacity to process these subsidies based on the predictability and timing of the resource pulse. Such mortality events may be increasing in frequency and severity with global environmental change, and therefore a more robust understanding of their ecological effects is needed to inform theory and application.

\section{BACKGROUND AND CONCEPTUAL FRAMEWORK}

The collection of papers in this Special Issue of FEE, Death and Decomposition in Aquatic Ecosystems, documents a range of animal mortality events that have substantial documented ecosystem effects. The authors collectively demonstrate that animal death and decomposition, or contributions of dead organic matter from riparian zones, can have profound ecosystem effects independent of the predation process. Further, mass mortality events (MMEs) are significant phenomena that punctuate functional processes in terrestrial and aquatic ecosystems across the globe. In their seminal meta-analysis, Fey et al. (2015) assembled published reports of 727 MMEs based on a functional definition of an MME-namely, the rapid catastrophic die-off of multiple organisms in a single event. Fey et al. (2015) conclude that the largest magnitude MMEs result from starvation, disease, or multiple stressors, such as drought and long-distance migration 
in terrestrial ecosystems or eutrophication and oxygen depletion in aquatic environments. However, in this Special Issue, the authors also consider the "programmed" death of organisms that results from life-history traits, such as spawning migrations or life stage transitions (cf. Lamberti et al., 2010).

In general, reports of MMEs have been increasing in frequency since reasonably reliable records began to be kept in the 1940s. Fey et al. (2015; see their Figure 1) cataloged die-offs of five vertebrate animal groups-mammals, birds, amphibians, reptiles, and fish-along with the general category of invertebrates. Fish die-offs represented more than half of all reported MMEs, whereas reptile and invertebrate die-offs were least common or least reported. The latter aspect of reporting is significant, since mortality in taxa such as fish or mammals may be more likely to be documented than die-offs of insects or other invertebrates. Regardless, die-offs in most groups showed an increasing frequency of occurrence over the past 75 years, involving an increasing number of individuals for most taxa (Fey et al., 2015; see their Figure 2). The apparent increase in MMEs over time may be due to growing interest in the phenomenon by the scientific community but also rapidly increasing publication activity over that period, as the frequency of MMEs broadly tracks the number of literature citations for particular animal groups. Furthermore, as global change accelerates, interest in MMEs has increased related to habitat loss, climate change, biological invasions, and animal overharvest (Sala et al., 2000).

As largely unpredictable events, MMEs often lack quantitative information on their magnitude beyond rough estimates of the number of individuals that died. For example, few studies report metrics important to assess mass contributions to ecosystems, such as total biomass (wet or dry) or elemental composition of the carrion. Therefore, we collected data from several MMEs for which relatively robust information was available on the mass of animal carrion resulting from the event and the stoichiometry of the major nutrients $(\mathrm{C}, \mathrm{N}, \mathrm{P})$ in the dead tissue, either from the original or related publications. For seven such MMEs (Figure 1A), the animal dry mass of these events ranged from $1.7 \mathrm{mT}$ (dry mass) for an episodic die-off of Corbicula clams in a $10-\mathrm{km}$ reach of the Broad River, GA, USA, to $301 \mathrm{mT}$ for wildebeest in the Mara River of the Maasai Mara in Kenya, Africa. Other taxa found in specific systems show a broad range in mass contributions to aquatic or riparian ecosystems (Figure 1A). The stoichiometry (i.e., C:N:P ratio) of this biomass also varied substantially among taxa (Figure 1B). After normalizing to $\mathrm{P}$ (i.e., $\mathrm{P}$ set at 1.0 ), wildebeest had the lowest $\mathrm{C}: \mathrm{N}: \mathrm{P}$ ratio of 21:4:1, suggesting a relatively rich $\mathrm{P}$ source, whereas cicadas had the highest ratio at 195:33:1, suggesting a depleted $\mathrm{P}$ source. The two insect taxa (cicadas and midges) had the highest ratios overall likely because of the high $\mathrm{C}$ content and mass of the exoskeleton relative to internal tissues. Fish had overall favorable stoichiometry relative to the Redfield ratio (i.e., 106:16:1), varying from 48:8:1 for cichlids to 131:17:1 for pink salmon.

Fish are the most common MMEs recorded in the literature (Fey et al., 2015), in part due to the predictable annual spawning migrations of some taxa that exert high physiological stress or genetically-determined death. For example, annual salmon spawning migrations in rivers throughout the world generate a large and predictable pulse of dead biomass in those ecosystems. Marine fish in the family Clupeidae (e.g., alewife, shad, herring) also undergo annual spawning migrations, often resulting in substantial mortality in freshwater ecosystems (Durbin et al., 1979). In contrast, fish die-offs from environmental stressors (e.g., eutrophication, elevated temperature, dissolved oxygen depletion), sometimes exacerbated by metabolism of the fish themselves, can deposit unpredictable pulses of biomass in space and time such as with cichlid fish in a Brazilian reservoir (Starling et al., 2002) or have strong ecosystem effects as for salmon in southeast Alaska streams (Sergeant et al., 2017). Even without mass mortality, Nobre et al. argue in this issue that fish (gizzard shad) carcasses in Ohio (USA) lakes are net nutrient sources to the water column over decadal scales even while live fish are net nutrient sinks at an annual scale. They compute that an amazing 99\% of the nitrogen and phosphorus from these fish is efficiently mineralized in the water column and thus available for uptake by plankton.

Aquatic invertebrates are often overlooked sources of ecosystem alteration due to synchronous mass mortalities. Sedentary organisms can be most sensitive to human alteration of ecosystems. For example, MMEs of freshwater unionid mussels, many of which are imperiled, can have significant and lasting ecological effects including losses in biofiltration, nutrient cycling, and nutrient storage (e.g., Vaughn et al., 2015). In this issue, DuBose et al. warn that unionid dieoffs in rivers are accelerating due the dual impacts of drought and temperature increase resulting from climate change. While such dieoffs can produce short-term beneficial nutrient pulses, declines in these long-lived organisms can result in permanent loss of ecosystem function.

Further, die-offs of invasive bivalves (e.g., Corbicula spp., dreissenid mussels) can affect both instream and riparian nutrient dynamics and scavenger communities (Mouthon, 2001; Novais et al., 2015). Bivalve death also elicits unique long-term effects through the mass availability of recalcitrant shells that can take decades to decompose and offer new habitat availability and slowly released sources of calcium and phosphorus (e.g., Wenger et al., 2018). In this issue, McDowell and Sousa suggest that invasive mussels are less able to tolerate extreme abiotic conditions (e.g., in hydrology or temperature) than are native mussels and therefore are more prone to mass dieoffs. Such dieoffs release nitrogen pulses and shells alter habitat, while decomposition exerts oxygen stress on other organisms resulting in cascading ecosystem impacts.

Insects often undergo synchronous mass mating emergences followed quickly by egg-laying and death. For example, emergent insects from soils (cicadas in North American gallery forests; Whiles et al., 2001; Yang, 2004) and lakes [chironomid midges in Lake Mývatn, Iceland (Dreyer et al., 2015); chaoborid midges in Lake Malawi, Africa (Irvine, 2000)] produce large quantities of biomass that is disseminated in surrounding ecosystems and sometimes even used as a human food subsidy (Williams and Williams, 2017). In reality, the pathway of organic matter exchanges between aquatic and terrestrial ecosystems is bidirectional. In this issue, Entrekin et al. describe how declines in carbon inputs to streams (in 

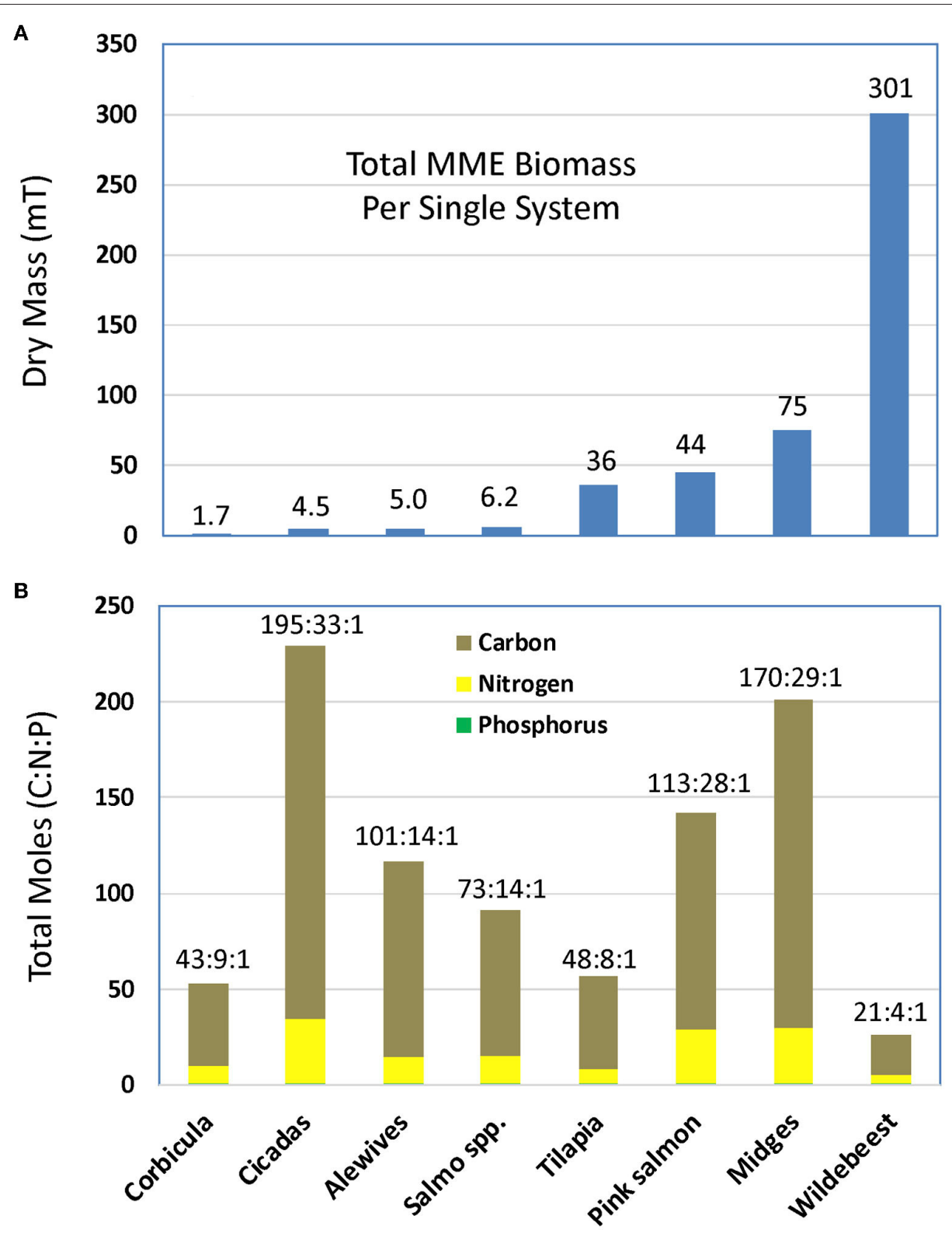

FIGURE 1 | (A) Total dry mass ( $\mathrm{mT}$ ) and (B) molar stoichiometry of carbon (C), nitrogen (N), and phosphorus (P) for a single mass mortality event (MME) in a single system (e.g., river, lake) of Asiatic clams Corbicula fluminea (McDowell et al., 2017), periodical cicadas Magicicada cassini (Whiles et al., 2001), alewives Alosa pseudoharengus (Durbin et al., 1979), Atlantic salmon and brown trout Salmo spp. (Lyle and Elliott, 1998), cichlid fish Tilapia spp. and Oreochromis spp. (Starling et al., 2002), pink salmon Oncoryhnchus gorbuscha (Helfield and Naiman, 2001), chironomid midges Chironomus islandicus and Tanytarsus gracilentus (Dreyer et al. 2015), and wildebeest Connochaetes taurinus (Subalusky et al., 2017). Total biomass or stoichiometric ratio is given above each bar.

the form of large wood and organic debris) can cascade into reductions in ecosystem function. When large wood was added back to a temperate stream, carbon flow through the food web was stimulated, resulting in a $20 \%$ increase in macroinvertebrate production. Therefore, donations of organic matter between aquatic and terrestrial ecosystems represent a dynamic process that often interfaces through the activities of invertebrates.

\section{SELECTED EXAMPLES OF MASS MORTALITY EVENTS}

As demonstrated in this Special Issue, the examples of MMEs are diverse and global, but all have the potential to pulse animal carrion into ecosystems and potentially to deliver that biomass across traditional ecosystem boundaries. Below we provide three examples of MMEs that either can drive ecosystem change 
or respond to environmental change relevant to freshwater ecosystems. These examples highlight several of the topics explored in this Special Issue augmented with other published accounts of MMEs.

\section{Spawning Runs of Pacific Salmon}

In aquatic ecosystems, Pacific salmon (Oncorhynchus spp.) provide a classic example of mass mortality and have been the topic of hundreds of studies over the past two decades (see reviews by Schindler et al., 2003; Janetski et al., 2009), reflecting their ecological, economic, and sociocultural importance in the northern Pacific rim (Gende et al., 2002). Most salmon species typically undertake a predictable (i.e., spatial, temporal) annual migration from the ocean to freshwater for a single semelparous spawning event that culminates in death. When adult salmon return to freshwater they deposit so-called "marine-derived nutrients" in natal ecosystems as gametes, carcasses, and excretory products, often with pervasive and dramatic ecological effects (Tiegs et al., 2011).

The most dramatic aspect of the salmon mass spawning event is simply the magnitude of the flux (Larkin and Slaney, 1997) and the dependency of ecosystems and associated organisms upon this material (Cederholm et al., 1999). In Alaska (USA) alone, since 1975, an average of approximately 150 million Pacific salmon have been commercially harvested annually (most offshore), producing over 300 million $\mathrm{kg}$ of fish for human and animal consumption [Alaska Department of Fish Game (ADFG), 2019]. Individuals that are harvested do not contribute to the mass die-off following spawning and therefore to the resource subsidy to freshwater, estuarine, and adjacent terrestrial ecosystems. However, the very magnitude of this number represents a substantial movement of carbon and nutrients from the ocean to the terrestrial environment. Specific data for the total abundance of dead spawning salmon do not exist, but rough estimates place the number at 150 million salmon spawners in Alaska, about equal to those harvested commercially (Munro, 2018).

Given the putative stoichiometric ratio of an average fish (Figure 1B; see also Larkin and Slaney, 1997), this migration annually transports and deposits an estimated 150 million $\mathrm{kg}$ C, 15 million $\mathrm{kg} \mathrm{N}$, and 2 million $\mathrm{kg} \mathrm{P}$ as highly labile compounds into freshwaters. Recently, we have learned that micronutrients from these carcasses also may be important to recipient ecosystems (Currier et al., 2020). Moreover, this predictable and sustained flux enters systems that are otherwise nutrient-poor and at a time of year (often autumn) when productivity is limited by declining temperatures and light levels (Gende et al., 2002). In this issue, Harding et al. discuss how the effects of these carcass resource subsidies on spawning rivers, surrounding riparian forests, and their estuaries can vary with watershed landscape structure, salmon species that are spawning, size of the run, and the vertebrate scavengers in the local area. In their British Columbia (Canada) watersheds, bears and wolves were the major vectors of salmon into riparian zones, while salmon density and watershed size drove the "leakage" of carcasses into estuaries.

The vision of salmon runs feasted upon by bears and other macro-predators elicits awe in observers and notions of short food chains. In this issue, however, Larson et al. use molecular approaches to explore the microbiome in salmon streams and make the case that salmon decomposition subsidizes the microbial loop. Salmon do this by providing essential nutrients but also by introducing novel microorganisms into the ecosystem. This process is facilitated by macroinvertebrates that graze on carcasses and then harbor in their guts, and potentially transfer, novel microbes during their feeding and excretion. In this issue, Rüegg et al. further point out that spawning salmon are both a source of nutrients (from their bodies) but also a source of disturbance (from nest-building) to benthic biota. Biofilm often responds with increases in biomass early in the salmon run, declines during active nest building, and then another increase during carcass decomposition, as verified by stable isotopes.

Thus, salmon mass die-offs connect multiple ecosystems, and represent a potentially important "resource injection" for both aquatic and terrestrial organisms, plant as well as animal, at a critical time in these ecosystems. However, evidence is increasing of a potential "dark side" of salmon migrations especially where they have been introduced as a sport fish. In this issue, Gerig et al. review a body of recent literature documenting how Pacific salmon introduced into the Laurentian Great Lakes now accumulate, transport, and deposit contaminants (especially persistent organic pollutants, or POPs) in Great Lakes spawning tributaries where they have become naturalized. Riverine fish that do not migrate now carry the toxic imprint of these salmon via food web transfer, particularly through egg consumption. This POP biotransport is now also being reported in remote southern hemisphere rivers (e.g., Patagonia) where Pacific salmon have been introduced (Montory et al., 2020).

\section{Migration and Seasonal Death in Wildebeest}

A dramatic example of an MME involving a terrestrial herbivore providing a whole-body resource subsidy to an aquatic environment is the mass migration of wildebeest (Connochaetes taurinus) in Kenya and Tanzania of eastern Africa. A wide range of biomass inputs from MMEs exist (Figure 1A), but wildebeest fatalities during their multiple crossings of the Mara River yield the highest biomass contribution to a single system of the studies yet conducted (Subalusky et al., 2017). In one of the largest annual migrations on Earth, approximately one million wildebeest migrate through the Serengeti and arrive in the Maasai Mara region of Kenya in summer where they remain until late autumn. Large herds regularly cross the Mara River, and the mortality associated with crossings is influenced by a combination of recent precipitation (driving river discharge), river geomorphology, herd size, and riverine predators.

With a mean wildebeest body wet mass of $175 \mathrm{~kg}$, mass drownings deposit an estimated 570-1622 metric tons of biomass (156-446 metric tons dry biomass) in the river annually (Subalusky et al., 2017) with an elemental composition of $36 \%$ 


\section{Predictability of MME}

\section{LOW}

\section{Catastrophic Dieoffs} Amphibians

Seals

\section{Cetaceans}

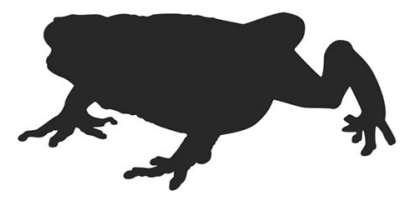

Seasonal

Kills

Tilapia

Wildebeest

Clams

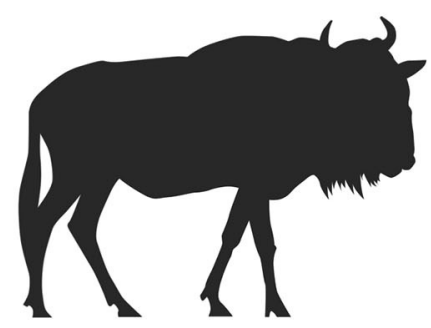

HIGH

\section{Life History \\ Features}

\author{
Salmon
}

Alewives

Midges

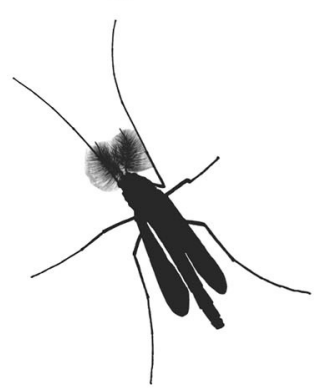

FIGURE 2 | Conceptual diagram depicting a predictability gradient of mass mortality events, and therefore possible ecosystem effects, ranging from catastrophic die-offs (left-hand side) to programmed death (right-hand side) with example organisms.

C, $8 \% \mathrm{~N}$, and $4 \% \mathrm{P}$ by mass. Carcasses tend to accumulate in regions of slow flow, where they fuel nutrient cycling and food webs as they decompose. During this MME, more dead biomass is deposited per unit river length than even during a typical Pacific salmon run. Scavengers and decomposers that exploit this resource are very diverse and include fish, crocodiles, hippopotamus, vultures, and other birds that congregate on the carcasses. In this issue, Subalusky et al. highlight the large pool of phosphorus represented by the massive amount of wildebeest bones deposited in the river that can persist for decades. In a two-stage process, bones leach mainly nitrogen initially, but then leak phosphorus for decades. The rich biofilm that grows on these bones supports $19 \%$ of macroinvertebrate and $24 \%$ of fish growth in the river, as revealed by stable isotopes. In this sense, Subalusky et al. fittingly refer to the Mara River as a "river of bones" that brings added attention to importance of bones in other ecosystems.

The influence of vertebrate death and decomposition on aquatic ecosystems depends on the magnitude, history, and recurrence of the mortality event, as emphasized by Benbow et al. in their introduction to this issue. Salmon and wildebeest represent reasonably predictable subsidies of carcass material to aquatic ecosystems, but even these are dependent on numbers of individuals and river hydrology during the migratory season. Benbow et al. note that the high nutrient and caloric density of carrion makes this material particularly important to energy-limited food webs (e.g., rivers) that may otherwise be dependent on lower-quality plant detritus to fuel production. Such necrophagy can have profound influences on many aquatic ecosystems.

\section{Mass Emergence and Death in Insects}

Insect emergence can be a substantial source of biomass for associated ecosystems, especially during synchronous emergences. These contributions are bidirectional between aquatic and terrestrial ecosystems, with riparian areas providing transitional habitats. Cicadas (Hemiptera) undergo cyclical mass emergences (i.e., nymph to winged adult) from forest soils (Yang, 2004), and can contribute to aquatic and riparian processes during death and decomposition. For example, the mass emergence (150 individuals $\mathrm{m}^{-2}$ ) and death of 17-year periodical cicadas (Magicicada cassini) represented a substantial $\mathrm{N}$ flux (up to $3 \mathrm{~g} \mathrm{~N} \mathrm{~m}^{-2}$ ) to riparian gallery forests of the Kings Creek watershed in Kansas, USA (Whiles et al., 2001). These cicadas had high relative C content (C:N:P $=195: 33: 1)$ likely due to chitin in their exoskeleton, reasonable $\mathrm{N}$ content, and 
low $\mathrm{P}$ content. Therefore, direct consumption or decomposition would represent a good $\mathrm{N}$ source but relatively poor $\mathrm{P}$ source. In freshwater ecosystems, many species of aquatic insects emerge en masse (e.g., Ephemeroptera), and then mate and die in a matter of hours to days. These aquatic mass emergences and subsequent deaths are important resource subsidies to adjacent riparian forests as well as aquatic food webs themselves during egg-laying (Baxter et al., 2005). The stunning mass emergences of Hexagenia mayflies from the Mississippi River and Great Lakes (USA) are visible on weather radar and can inject up to 88 billion individuals and 3,000 $\mathrm{mT}$ of biomass into the airspace and later back to ecosystems (Stepanian et al., 2020). However, recent declines in mayfly abundance have caused grave concern about loss of these resource subsidies and other ecosystem services that they provide.

Mass emergences of chironomid midges (Diptera) from lakes are common phenomena that can serve as a link between aquatic and terrestrial ecosystems. Dreyer et al. (2015) estimated midge (Chironomus islandicus and Tanytarsus gracilentus) emergences and fluxes along the shore of Lake Mývatn ("midge lake") in Iceland. As larvae, these midges feed on detritus and biofilm on the lake bottom. After pupating, individuals float to the surface, emerge as adult flies, and mate in swarms near aquatic habitat. After egg-laying, dead midges contribute biomass to both the lake and shore, mostly within $100 \mathrm{~m}$ of the lake, thereby providing an aquatic to terrestrial resource subsidy. In Lake Mývatn, mass emergences occur in late spring to early summer with periodic (5-8 years) cycles of high abundance. Total annual $\mathrm{N}$ flux to shores was estimated to be $12 \mathrm{~kg}$ per hectare, increasing the available nitrogen in the soil surrounding the lake, and total annual $\mathrm{P}$ input was $\sim 1 \mathrm{~kg}$ per hectare. Return inputs to Lake Mývatn are more difficult to estimate, but likely also represent a return flux of nutrients to the lake. Hoekman et al. (2019) show that terrestrial arthropod predators decline in abundance in plots where midges are excluded, and display stable isotope enrichment when allowed access to midge prey. The availability of emergent midges may also coincide with bird migrations to the lake. In addition to chironomid midges, lakes of Africa also have substantial mass emergence events of phantom midges (Diptera: Chaoboridae) and some mayflies (Ephemeroptera: Polymitarcyidae) that provide significant energy and nutrients to adjacent landscapes (Okedi, 1992; Allison et al., 1996).

\section{GENERAL PARADIGM}

In summary, the examples provided suggest that mass mortalities exist along a predictability gradient, where programmed death

\section{REFERENCES}

Alaska Department of Fish and Game (ADFG) (2019). All Salmon Species Combined Historical Harvest Rankings. Available online at: http://www.adfg. alaska.gov/index.cfm?adfg=commercialbyfisherysalmon.salmon_combined_ historical

Allison, E., Irvine, K., and Thompson, A. (1996). Lake flies and the deepwater demersal fish community of Lake Malawi. J. Fish Biol. 48, 1006-1010. doi: 10.1111/j.1095-8649.1996.tb01494.x is predictable and repeatable, whereas catastrophic die-offs are unpredictable and sporadic (Figure 2). Intermediate are seasonal die-offs that have varying magnitude from year to year, if they occur at all, and can respond to variable environmental conditions. However, except for a few notable exceptions (e.g., Pacific salmon, wildebeest), we know surprisingly little about the ecosystem impacts of these mortality events, many of which are linked to migrations that are declining at a global scale (Wilcove and Wikelski, 2008). Poorly detailed observations of MMEs, largely a result of their unpredictable nature, rarely allow us to compute mass-balance estimates. Even when care is taken to note the number or biomass of the dead, limited analyses of animal C:N:P exist from which to draw strong ecological conclusions about stoichiometric influences. Detailed biomass estimates and decomposition studies, followed through time, may allow us to understand the fate of carcass material left in the environment, and the pathways that are followed within and beyond an ecosystem. Furthermore, food web analysis, specifically determining the stoichiometric ratios, biomass, and pathways by which material flows, would be valuable in determining the fate of ecological subsidies provided by the event. Clearly, when thoroughly investigated, mass mortality events could drive ecosystem-wide changes in nutrient cycling, productivity, distributional ranges, and biodiversity. Ongoing global environmental change may drive systems toward less predictable mass mortality or changes in the magnitude and frequency of these important events.

\section{AUTHOR CONTRIBUTIONS}

GL, NL, DC, and MEB contributed to the writing and revision of this manuscript. MAB analyzed data from the published literature and produced Figure 1. All authors contributed to the article and approved the submitted version.

\section{FUNDING}

The authors were supported by their home institutions to produce this manuscript.

\section{ACKNOWLEDGMENTS}

This manuscript and Special Issue emanated from a symposium held at the Annual Meeting of the Society for Freshwater Science in May 2018 in Detroit, MI, USA. We thank all the participants in that symposium. Helen Kimbell at FEE helped to guide the publication of this manuscript.

Baxter, C. V., Fausch, K. D., and Saunders, W. C. (2005). Tangled webs: reciprocal flows of invertebrate prey link streams and riparian zones. Freshw. Biol. 50, 201-220. doi: 10.1111/j.1365-2427.2004.01328.x

Cederholm, C. J., Kunze, M. D., Murota, T., and Sibatani, A. (1999). Pacific salmon carcasses: essential contributions of nutrients and energy for aquatic and terrestrial ecosystems. Fisheries 24, 6-15. doi: 10.1577/1548-8446(1999)024<0006:PSC>2.0.CO;2

Currier, C. M., Chaloner, D. T., Rüegg, J., Tiegs, S. D., D’Amore, D., and Lamberti, G. A. (2020). Beyond nitrogen and phosphorus subsidies: Pacific salmon 
(Oncorhynchus spp.) as potential vectors of micronutrients. Aquat. Sci. 82:50. doi: 10.1007/s00027-020-00725-z

Dreyer, J., Townsend, P. A., Hook, J. C. III., Hoekman, D., Vander Zanden, M. J., and Gratton, C. (2015). Quantifying aquatic insect deposition from lake to land. Ecology 96, 499-509. doi: 10.1890/14-0704.1

Durbin, A. G., Nixon, S. W., and Oviatt, C. A. (1979). Effects of the spawning migration of the alewife, Alosa pseudoharengus, on freshwater ecosystems. Ecology 60, 8-17. doi: 10.2307/1936461

Fey, S. B., Siepielski, A. M., Nusslé, S., Cervantes-Yoshida, K., Hwan, J. L., Huber, E. R., et al. (2015). Recent shifts in the occurrence, cause, and magnitude of animal mass mortality events. Proc. Natl. Acad. Sci. U.S.A. 112, 1083-1088. doi: $10.1073 /$ pnas. 1414894112

Gende, S. M., Edwards, R. T., Willson, M. F., and Wipfli, M. S. (2002). Pacific salmon in aquatic and terrestrial ecosystems: Pacific salmon subsidize freshwater and terrestrial ecosystems through several pathways, which generates unique management and conservation issues but also provides valuable research opportunities. Bioscience 52, 917-928. doi: 10.1641/0006-356820020520917:PSIAAT2.0.CO;2

Helfield, J. M., and Naiman, R. J. (2001). Effects of salmon-derived nitrogen on riparian forest growth and implications for stream productivity. Ecology 82, 2403-2409. doi: 10.1890/0012-965820010822403:EOSDNO2.0.CO;2

Hoekman, D., McCary, M. A., Dreyer, J., and Gratton, C. (2019). Reducing allochthonous resources in a subarctic grassland alters arthropod food webs via predator diet and density. Ecosphere 10:e02593. doi: 10.1002/ecs2.2593

Irvine, K. (2000). Macrodistribution, swarming behaviour and production estimates of the lakefly Chaoborus edulis (Diptera: Chaoboridae) in Lake Malawi. Adv. Ecol. Res 31, 431-448. doi: 10.1016/S0065-2504(00)31023-6

Janetski, D. J., Chaloner, D. T., Tiegs, S. D., and Lamberti, G. A. (2009). Pacific salmon effects on stream ecosystems: a quantitative synthesis. Oecologia 159, 583-595. doi: 10.1007/s00442-008-1249-x

Lamberti, G. A., Chaloner, D. T., and Hershey, A. E. (2010). Linkages among aquatic ecosystems. J. North Am. Benthol. Soc 29, 245-263. doi: 10.1899/08-166.1

Larkin, G. A., and Slaney, P. A. (1997). Implications of trends in marinederived nutrient influx to south coastal British Columbia salmonid production. Fisheries 22, 16-24. doi: 10.1577/1548-84461997022<0016:IOTIMN > 2.0.CO;2

Lyle, A. A., and Elliott, J. M. (1998). Migratory salmonids as vectors of carbon, nitrogen and phosphorus between marine and freshwater environments in north-east England. Sci. Total Environ. 210-211, 457-468. doi: 10.1016/S0048-9697(98)00031-X

McDowell, W. G., McDowell, W. H., and Byers, J. E. (2017). Mass mortality of a dominant invasive species in response to an extreme climate event: implications for ecosystem function. Limnol. Oceanogr. 62, 177-188. doi: 10.1002/lno.10384

Montory, M., Habit, E., Fernandez, P., Grimalt, J. O., Kolok, A. S., Barra, R. O., et al. (2020). Biotransport of persistent organic pollutants in the southern Hemisphere by invasive Chinook salmon (Oncorhynchus tshawytscha) in the rivers of northern Chilean Patagonia, a UNESCO biosphere reserve. Environ. Int. 142:105803. doi: 10.1016/j.envint.2020.105803

Mouthon, J. (2001). Life cycle and population dynamics of the Asian clam Corbicula fluminea (Bivalvia: Corbiculidae) in the Saone River at Lyon (France). Hydrobiologia 452, 109-119. doi: 10.1023/A:1011980011889

Munro, A. R. (2018). Summary of Pacific Salmon Escapement Goals in Alaska with a Review of Escapements From 2009 to 2017. Alaska Department of Fish and Game, Fishery Manuscript Series No. 18-04, Anchorage, AK.

Novais, A., Souza, A. T., Ilarri, M., Pascoal, C., and Sousa, R. (2015). From water to land: how an invasive clam may function as a resource pulse to terrestrial invertebrates. Sci. Total Environ. 538, 664-671. doi: 10.1016/j.scitotenv.2015.08.106
Okedi, J. (1992). Lake flies in Lake Victoria: their biomass and potential for use in animal feeds. Int. J. Trop. Insect Sci. 13, 137-144. doi: 10.1017/S1742758400013990

Sala, O. E., Chapin, F. S. III., Armesto, J. J., Berlow, E., Bloomfield, J., Dirzo, R., et al. (2000). Global biodiversity scenarios for the year 2100. Science 287, 1770-1774. doi: $10.1126 /$ science.287.5459.1770

Schindler, D. E., Scheuerell, M. D., Moore, J. W., Gende, S. M., Francis, T. B., and Palen, W. J. (2003). Pacific salmon and the ecology of coastal ecosystems. Front. Ecol. Environ 1, 31-37. doi: 10.1890/1540-929520030010031:PSATEO2.0.CO;2

Sergeant, C. J., Bellmore, J. R., McConnell, C., and Moore, J. W. (2017). High salmon density and low discharge create periodic hypoxia in coastal rivers. Ecosphere 8:e01846. doi: 10.1002/ecs2.1846

Starling, F., Lazzaro, X., Cavalcanti, C., and Moreira, R. (2002). Contribution of omnivorous tilapia to eutrophication of a shallow tropical reservoir: evidence from a fish kill. Freshw. Biol 47, 2443-2452. doi: 10.1046/j.1365-2427.2002.01013.x

Stepanian, P. M., Entrekin, S. A., Wainwright, C. E., Mirkovic, D., Tank, J. L., and Kelly, J. F. (2020). Declines in an abundant aquatic insect, the burrowing mayfly, across major North American waterways. Proc. Natl. Acad. Sci. U.S.A. 117, 2987-2992. doi: 10.1073/pnas.1913598117

Subalusky, A. L., Dutton, C. L., Rosi, E. J., and Post, D. M. (2017). Annual mass drownings of the Serengeti wildebeest migration influence nutrient cycling and storage in the Mara River. Proc. Natl. Acad. Sci. U.S.A. 114, 7647-7652. doi: 10.1073/pnas.1614778114

Tiegs, S. D., Levi, P. S., Rüegg, J., Chaloner, D. T., Tank, J. L., and Lamberti, G. A. (2011). Ecological effects of live salmon exceed those of carcasses during an annual spawning migration. Ecosystems 14, 598-614. doi: 10.1007/s10021-011-9431-0

Vaughn, C. C., Atkinson, C. L., and Julian, J. P. (2015). Drought-induced changes in flow regimes lead to long-term losses in mussel-provided ecosystem services. Ecol. Evol. 5, 1291-1305. doi: 10.1002/ece3.1442

Wenger, S. J., Subalusky, A. L., and Freeman, M. C. (2018). The missing dead: the lost role of animal remains in nutrient cycling in North American Rivers. Food Webs 16:e00106. doi: 10.1016/j.fooweb.2018.e00106

Whiles, M. R., Callaham, M. A. Jr., Meyer, C. K., Brock, B. L., and Charlton, R. E. (2001). Emergence of periodical cicadas (Magicicada cassini) from a Kansas riparian forest: densities, biomass and nitrogen flux. Am. Midl. Nat. 145, 176-187. doi: 10.1674/0003-003120011450176:eopcmc 2.0.co;2

Wilcove, D. S., and Wikelski, M. (2008). Going, going, gone: is animal migration disappearing? PLoS Biol. 6:e188. doi: 10.1371/journal.pbio.0060188

Williams, D. D., and Williams, S. S. (2017). Aquatic insects and their potential to contribute to the diet of the globally expanding human population. Insects 8:72. doi: 10.3390/insects 8030072

Yang, L. H. (2004). Periodical cicadas as resource pulses in North American forests. Science 306, 1565-1567. doi: 10.1126/science.1103114

Conflict of Interest: The authors declare that the research was conducted in the absence of any commercial or financial relationships that could be construed as a potential conflict of interest.

Copyright (c) 2020 Lamberti, Levesque, Brueseke, Chaloner and Benbow. This is an open-access article distributed under the terms of the Creative Commons Attribution License (CC BY). The use, distribution or reproduction in other forums is permitted, provided the original author(s) and the copyright owner(s) are credited and that the original publication in this journal is cited, in accordance with accepted academic practice. No use, distribution or reproduction is permitted which does not comply with these terms. 